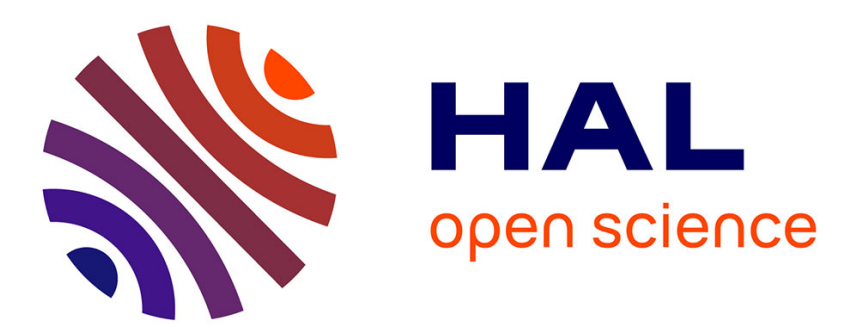

\title{
Auxiliary Selection with Intransitive and Reflexive Verbs: the limits of gradience and scalarity, followed by a proposal \\ Pierre-Don Giancarli
}

\section{To cite this version:}

Pierre-Don Giancarli. Auxiliary Selection with Intransitive and Reflexive Verbs: the limits of gradience and scalarity, followed by a proposal. Éd. Kailuweit, Rolf / Rosemeyer, Malte. Auxiliary Selection Revisited: Gradience and Gradualness, coll. linguae \& litterae, vol. 44, De Gruyter, p. 79-120, 2015, 978-3-11-034886-6. 10.1515/9783110348866-004 . hal-01634488

\section{HAL Id: hal-01634488 \\ https://hal.science/hal-01634488}

Submitted on 13 Dec 2017

HAL is a multi-disciplinary open access archive for the deposit and dissemination of scientific research documents, whether they are published or not. The documents may come from teaching and research institutions in France or abroad, or from public or private research centers.
L'archive ouverte pluridisciplinaire HAL, est destinée au dépôt et à la diffusion de documents scientifiques de niveau recherche, publiés ou non, émanant des établissements d'enseignement et de recherche français ou étrangers, des laboratoires publics ou privés. 
Pierre-Don Giancarli, Université de Poitiers

\section{Auxiliary selection with intransitive and reflexive verbs: the limits of gradience and scalarity, followed by a proposal. ${ }^{1}$}

In: Auxiliary Selection Revisited: Gradience and Gradualness, Rolf Kailuweit \& Malte Rosemeyer (eds), FRIAS book series "Linguae \& Litterae", vol. 44, De Gruyter, Berlin/Münich/Boston, 2015, p. 79-120.

\section{Introduction}

The Auxiliary Selection Hierarchy (ASH, Sorace 2000, also called Split Intransitivity Hierarchy, Sorace 2006, 2011) is today's most elaborate gradient representation dedicated to the auxiliary selection of $\mathrm{BE}$ or $\mathrm{HAVE}^{2}$ within intransitive verbs. Nevertheless, I wish to emphasise the limits of gradience before proposing a binary and therefore non-gradient and even non-scalar representation of auxiliaries including both intransitive and reflexive verbs.

This is not the first binary attempt in the literature: according to the Unaccusative Hypothesis (UH), unaccusatives select BE and unergatives select HAVE. ${ }^{3}$ The UH was initially proposed in Relational Grammar in Perlmutter (1978) and was adapted into the Government-Binding theory elaborated by Burzio (1981, 1986). According to the UH there are two types of intransitives that differ syntactically: the single argument (and surface subject) of an unergative is an external argument equivalent to the subject of a transitive verb, while the single argument (and surface subject) of an unaccusative is an internal argument equivalent to the direct object of a transitive verb promoted to subject position. It also claims that the distinction is systematically related to the semantic characteristics of these verbs: unergativity correlates with agentivity and unaccusativity correlates with patienthood (Perlmutter 1978; Van Valin 1990).

However, the UH had several flaws, for example mismatches across unaccusativity diagnostic tests, difficulty in explaining the differences between the patienthood of the subject of an intransitive inaccusative and that of the subject of a transitive verb in the passive, inconsistencies in the alignment between the syntactic and semantic properties of split intransitivity, some

\footnotetext{
${ }^{1}$ I am grateful to the two anonymous reviewers for their comments. Any error or inaccuracy is of course my own.

${ }^{2}$ Our spelling in upper case letters is meant to abstractly cover all the forms that auxiliaries can take in the various languages examined here, for example HAVE stands for FF avoir, Acadian aouèr and Corsican avè, all written in lower case letters.

${ }^{3}$ At least in Perlmutter 1978's and 1980's versions.
} 
verbs being unable to satisfy unaccusativity diagnostics in consistent ways while other verbs display either unaccusative or unergative syntax, etc. (see Rosen 1984; Levin and Rappaport Hovav 1995; Alexiadou et al. 2004; McFadden 2007; Giancarli 2011).

We wish to offer a different binary approach. This article is structured as follows. After drawing a distinction between scalarity and gradience, and basing myself explicitely on ASH publications and quotations from Sorace in particular, I argue in part 1 that gradience (not as an objective situation but as a possible representation of split intransitivity) is not an adequate representation of auxiliary selection, due to the problems raised by gradience as the particular representation developed by the ASH and due to a certain degree of mismatch with the data. Part 2 shows the problems posed by scalarity in general, drawing on authentic extracts from French, Acadian and Corsican ${ }^{4}$ corpora ${ }^{5}$. Part 3 provides a non-scalar global representation of auxiliaries in Corsican, including not only intransitive (non reflexive) verbs, which form a well-documented pattern, but also reflexive ones, which have received little attention in that respect.

\section{Gradience as the particular representation developed by the ASH 2.1 Gradience for intransitive verbs}

In terms of representation, I distinguish scalarity from gradience: scalarity refers to a scale made up of elements that are quantitatively different but qualitatively identical. It is a quantitative-only scale. Gradience is a particular kind of scale that makes relevant use of prototypicality (cf. Aarts 2007: 87, 107, 241). It refers to a scale built on one (or more) prototypical occurrence(s), consisting of occurrences that are both quantitatively and qualitatively different: some

${ }^{4}$ French here refers to the standard French spoken in France, FF for short. Traditional Acadian is a variety of French spoken in Eastern Canada both open to anglicisms and conservative regarding archaisms dating back to pre-classic French. Corsican is a Roman language with a pre-Roman substratum spoken in Corsica and northern Sardinia.

5 The Acadian corpus Péronnet "1985" from the University of Moncton is made up of recordings of French-speaking informants living in south-east New Brunswick, Canada. The Corsican corpus is composed mainly of novels and stories, either translations from French into Corsican, which will be useful when a comparison between the French and Corsican perfects is in order, or original texts in Corsican; see details in the Corpus section before the References. 
belong to the core(s) and are closer to the prototype(s), others belong to the periphery(ies). It is a quantitative and qualitative scale.

The ASH is all the more complex as it is not mono-dimensional but bi-dimensional, since it involves not a single class of elements but two classes of elements and an additional intermediate zone. It is gradience between two key categories (unaccusatives and unergatives $^{6}$ ) that converge on each other ${ }^{7}$, insofar as some verbs on the scale between the two ends display some characteristics of both categories (Aarts 2007: 55, 97, 124). The verbs situated at both ends are presented as prototypical of one or the other auxiliary ${ }^{8}$, they are central verbs (if one wishes to put it that way), while those in the middle are, paradoxically, peripheral.

In such a representation, the two parts of the scale are separated by an intermediate zone, a sort of zero-zone from which a part of the scale starts in one direction and another part in the opposite direction, which corresponds to the ASH underspecified verbs. A verb reaches its lowest level (of one and the other properties) in the middle of the scale, and reaches its highest levels at the ends, the maximum level of unaccusativity at one end of the scale, and the maximum level of unergativity at the other end. Does this apply to the unergative/unaccusative pair? In addition to some mismatches with the data, at least five difficulties can occur here:

${ }^{6}$ One reviewer requires quotations to substantiate this point: "The systematic differences within the syntactic classes of unaccusative and unergative verbs may be captured by a hierarchy" (Sorace 2004: 255); "Verbs at the BE end of the ASH are core unaccusatives [...]; verbs at the HAVE end are core unergatives" (Keller and Sorace 2003: 60), "There exist gradient dimensions or hierarchies which distinguish core unaccusative and unergative monadic verbs from progressively more peripheral verbs" (Legendre and Sorace 2003: 6); "The closer to the core a verb is, the more determinate its syntactic status as either unaccusative or unergative" (Sorace 2011: 69).

${ }^{7}$ I leave aside the question as to whether unaccusativity and unergativity, i.e. a dichotomy between verbs that take an internal argument and verbs that take an external argument, correspond to gradable properties. Proponents of the ASH have had to justify themselves on this point on many occasions ("The Split Intransitivity Hierarchy substantiates the intuition that, within their respective classes, some verbes are more unaccusative and more unergative than others [..] Crucially however this does not mean that unaccusativity or unergativity are inherently gradient notions" Sorace 2006: 110). I shall admit that, even if they are not gradable in themselves, they are amenable to scalar or gradient interpretations.

${ }^{8}$ HAVE for central unergative core verbs and peripheral verbs closer to the unergative core, $\mathrm{BE}$ for central unaccusative core verbs and peripheral verbs closer to the unaccusative core (Sorace 2004: 260-263). 


\subsubsection{Agentivity and telicity on the same scale?}

The ASH scale reduces unergativity to agentivity, and unaccusativity to telicity ${ }^{9}$, with BEverbs at the telic end, HAVE-verbs at the agentive one ${ }^{10}$ and verbs that are neither telic nor agentive in between, ${ }^{11}$ so that because agentivity and telicity are not pointing in opposite directions the question arises as to how they can be made to appear at the two opposite ends of one and the same scale.

Moreover, let us remember that some verbs can be telic and agentive at the same time: if one looks at the ASH category $\mathrm{n}^{\circ} 1$ (change of location), i.e. the verbs considered the most telic, like FF arriver (arrive), partir (leave), venir (come), revenir (come back) (Sorace 2000: 256), old Spanish huir (run away) and escapar (escape) (Legendre 2007), do they not bear an agentive component? One could easily argue that they do (cf. also Ruwet 1988: 385).

\subsubsection{Two asymmetric properties and mismatches with the data}

The second problem is that the roles played by the two properties that are supposed to stand in opposition are not equal but asymmetric: one is defined as the main factor, namely telicity. ${ }^{12}$ Because telicity is what distinguishes one end of the scale from the other end ${ }^{13}$, it covers the whole length of the scale,

\footnotetext{
${ }^{9}$ One reviewer requires quotations to substantiate this point: "I verbi intransitivi si collocano su un gradiente (Split Intransitivity Hierarchy) definito da due fattori: la telicità è l'agentività" [intransitive verbs are positioned on a gradient defined by two factors: telicity and agentivity] (Sorace's abstract in Sorace 2011: 67); "The array of verb classes represented on the Split Intransitivity Hierarchy reduces to two key factors: telicity and agentivity" (Sorace 2011: 69); "Verbs at the BE end of the ASH are core unaccusatives and denote telic change; verbs at the HAVE end are core unergatives and denote agentive activity" (Keller and Sorace 2003: 60); "Core verbs (those at the extremes of the hierarchy) are inherently specified for telicity and agentivity" (Sorace 2004: 265); "Telic change appears to be the core (prototypical) feature of unaccusative semantics" (Bentley and Eyrthorsson 2003: 453). Unaccusative verbs, consequently the verbs selecting BE since unaccusativity is supposed to be in connection with the choice of auxiliary, would be telic; see also Sorace 2000: 884.

10 "The two key notions are telic change, which strongly correlates with BE, and agentive unaffecting process, which strongly correlates with HAVE" (Sorace 2000: 861-862).

11 "Intermediate verbs, which are neither telic nor agentive [...]" (Sorace 2004: 265).

12 "In languages that have auxiliary selection, telicity is the main factor" (Sorace and Keller 2005: 17). The importance of telicity as a criterion is a widely shared position, even outside and before the ASH, cf. Van Valin 1990; Tenny 1992; Borer 1994, etc.

13 "The primary distinction separating the unaccusatives [at one end of the hierarchy] from the unergatives [at the other end of the hierarchy] is aspectual telicity" (Gurman Bard, FrenckMestre and Sorace 2010: 329); "Telicity is the main factor that separates verbs which select E [BE] from verbs which select A [HAVE] (Legendre 2007: 13); "Telicity is the primary factor that separates BE-verbs from HAVE-verbs" (Sorace 2004: 265); "Across languages, telicity is the primary factor, separating BE verbs from HAVE verbs (Sorace 2011: 71).
} 
from a high degree of telicity at the top of the scale (the unaccusative end) to a low degree of telicity at the bottom (the unergative end). ${ }^{14}$

The other property (agentivity) is deemed less important, with a scope that does not cover the whole scale but is limited to the category of HAVE-verbs, i.e. the unergative portion of the scale ${ }^{15}$, i.e. just a portion of the scale. So the question is this: can one establish a scale on the basis of two key properties, one which covers the whole scale, and the other only on a part of it?

Moreover, a lot of data cannot be accomodated by the ASH, not to say that they are at odds with it: the ASH predicts that, across languages, telicity is the primary factor separating BE-verbs from HAVE-verbs (Sorace 2011). Let us consider Corsican data, representing about 350 BE-selecting intransitives according to our countings, and French data, 23 BE-selecting intransitives according to Benveniste's countings. ${ }^{16}$

Telicity plays no role with regard to French verbs such as rester or demeurer (stay). Legendre and Sorace noticed the paradoxical atelicity of these verbs ("de manière inattendue, quelques verbes atéliques dénotant l'absence de changement sélectionnent être", Legendre and Sorace 2003: 213), but this did not result in their questioning telicity as their main factor. Moreover, regardless of the context, telicity can only apply to verbs such as monter ( $g o$ up) or descendre (go down) because it is understood in a very broad sense that denotes delimited events with an endpoint,

${ }^{14}$ Telicity as well as agentivity are regarded by the ASH as "gradient notions" (Sorace 2000: 882).

15 The ASH publications on this subject all agree to admit that the criterion of agentivity is only relevant for the HAVE-portion of the scale (Sorace 2011: 71: "Across languages [...] agentivity further differentiates among atelic verbs of process", Sorace 2004: 265: "Agentivity is a secondary factor that differentiates among HAVE-verbs", Gurman Bard, Frenck-Mestre and Sorace 2010: 329: "A secondary distinction, agentivity, separates core unergatives from peripheral unergatives"), except one ASH publication that on the contrary argues that agentivity is only relevant for the BE-portion of the scale: "agentivity is a secondary factor that further distinguishes among BE verbs" (Keller and Sorace 2003: 88).

${ }^{16}$ Entrer (get in), sortir (get out), naître (be born), éclore (hatch) [doubtful], mourir (die), décéder (die), partir (leave), tomber (fall), échoir (fall due) [rare], aller (go), venir (come), survenir (appear; occur), advenir (happen), devenir (become), provenir (come from), parvenir (reach; manage), intervenir (intervene; take place), monter (go up), descendre (go down), rester (stay), accourir (run up, rush), arriver (arrive; succeed; happen), retourner (go back) (Benveniste 1974: 181). Demeurer (stay), paraître (appear) and passer (pass; become) could be added. 
such as arriver (arrive) (Sorace 2004: 246), as well as others expressing a direction without an endpoint, such as monter or descendre (Sorace 2000: 865). In Legendre and Sorace (2003: 212) these verbs are directly added to the list of exceptions.

Any exception to the relatively short list of French verbs is all the more problematic for the ASH, since French BE-selecting verbs are supposed to identify a subset of intransitives at the BE-end of the hierarchy, i.e. the most unaccusative and telic part of the ASH gradient (Legendre and Sorace 2003: 225).

The same argument could be used for Corsican firmà / ristà / rimane (stay), cullà / salle (go up), scende / discende / scalà / falà / tramuntà (go down), continua and perdurà (go on). However in Corsican some verbs of activity such as girà (go round, move) or sfilà (parade) also select BE, as well as some verbs of state (see section 2.1.4.). These verbs also constitute a challenge for any attempt to characterise the selection of auxiliary BE in terms of telicity, ASH's pimary factor separating BE-verbs from HAVE-verbs, while they can be directly accounted for by our approach; see 4.1.4. and 4.1.2.

\subsubsection{Positioning of the 0-point}

The third problem, related to the previous question of asymmetric properties, is that this situation makes the positioning of the 0-point of the graduation difficult to understand: agentivity, limited to the unergative portion of the scale, has its highest degree at the bottom of the scale and its zero-point in the middle, whereas telicity has its highest degree at the top of the scale and its zero-point at the bottom. ${ }^{17}$ The question is: is the zero-zone in the middle of the scale, or at one of its ends?

\subsubsection{Fourth and fifth problem: the consequence this has on the verbs in the middle of the hierarchy and mismatches with the data}

If agentivity only applies to a portion of the scale, starting from a so-called zero-point in the middle and reaching its highest level at the bottom end, then the most gradient verbs (those directly concerned by variation since they admit competition between the two auxiliaries, and which, in Italian for example, are situated in the middle of the scale, see Legendre and Sorace 2003: 197 or Sorace

${ }^{17}$ In passing, this element contradicts what the reader might have previously understood regarding the intermediate zone, i.e. that the two mutually exclusive parts of the scale were separated by an intermediate zone standing for a zero-zone, the starting point for two opposite orientations. 
2004: 260) are least taken into account by the gradient representation developed by the ASH, since they are underspecified. ${ }^{18}$

Because they are both the least unaccusative and the least unergative, the most gradient verbs escape the two polar criteria. Moreover, if telicity applies to the whole length of the scale, then the middle of the hierarchy is occupied by state verbs, which display neither an average degree of telicity nor a varying degree of telicity according to the verbs under consideration, since by definition they are all atelic, with a zero-degree of telicity. This is a surprise, considering one is not looking at the bottom of the scale where the lowest degree of telicity can be found, but at the middle, which means that the verbs under examination are not situated at the expected place. ${ }^{19}$

Moreover, Corsican state verbs, far from being indeterminate, do not exhibit variation: most select HAVE categorically but some select BE in an equally categorical manner ${ }^{20}$. They cannot be explained with the ASH but they can be with our model, see 4.1.4.

${ }^{18}$ Cross-linguistically state verbs have an "underspecified aspectual structure" (Sorace 2000: 883); "Stative verbs tend to be variable across languages" (Sorace 2004: 249), "Intermediate verbs show variation" (Sorace 2004: 258); "Intermediate verbs are predicted to exhibit crosslinguistic variation" (Sorace 2011: 71); "Intermediate verbs, which are neither telic nor agentive, are the most variable and the least determinate" (Sorace 2004: 265); "Verbs that are stative and non-agentive are the most indeterminate and therefore the most susceptible to syntactic alternations and variation across languages" (Sorace 2011: 70).

${ }^{19}$ Verbs of category $\mathrm{n}^{\circ} 4$ are not the only ones to be not at the expected place: those belonging to category $\mathrm{n}^{\circ} 6$ (motional controlled processes) should clearly side with HAVE since they are almost at the very end of the HAVE part of the scale (6 out of 7). Yet German selects sein (BE) with a number of category 6 verbs, and so do Dutch and Italian (Legendre and Sorace 2003: 198). Conversely but based on the same logic, verbs belonging to category $\mathrm{n}^{\circ} 2$ (change of state) should clearly side with BE since they are almost at the very end of the BE part of the scale. Yet these verbs are not completely unresponsive to HAVE and some of them even accept it very well (Sorace 2000: 865, Legendre and Sorace 2003: 195-196, Sorace 2004: 259). Legendre and Sorace note that these verbs show "des alternances régulières [regularly alternate]": can one say of a verb that regularly alternates between BE and HAVE that it is stable, deeply rooted on the BE side? Also in German the relative order of the verbs on the scale is not the one expected either (Keller and Sorace 2003: 102). This difficulty was noticed, and the answer given was that "continuation of pre-existing state" verbs are not "continuation of pre-existing state" verbs, but "processes" (Keller and Sorace 2003: 102).

${ }^{20}$ Vive / campà (live), esiste (exist), occorre / bisugnà / vulè (be necessary), ghjuvà (be good), calzà / cunvene (suit), cunfà (be good), scunvene (be unsuitable), garbà / piace (please), spiace / dispiace (displease), durà (last), custà (cost), valè (be worth), bastà (be sufficient), mancà (be insufficient), etc. 


\subsection{Gradience for reflexive verbs?}

When dealing with auxiliary selection, one deals with intransitive verbs, and in doing so, one neglects - if not forgets - reflexives. The ASH does not take them into account, possibly because the languages under study do not display any auxiliary variation in their reflexive form (BE in Italian, BE in French...), and certainly because the ASH is limited to intransitive (monovalent) verbs, while reflexive verbs are dyadic (bivalent) (Cennamo and Sorace 2006: 88).

Nevertheless, an absence of auxiliary variation with the reflexive verbs of a language should not make the issue of its auxiliary selection less deserving of interest. Why should the selection of $\mathrm{BE}$ receive an explanation only when the verbs are monovalent and not bivalent? No reason is provided by the ASH. ${ }^{21}$ In fact, telicity, the main factor used by the ASH with regard to intransitives, has already been tested for reflexives and cannot be sustained for the latter. The ASH scholars who for a while supported telicity with intransitives compared with telic BE-selecting reflexives on the one hand and non-telic non-BE-selecting non-reflexives on the other hand (in pairs such as French ramollir/se ramollir (get soft) or Italian asciugarelasciugarsi (dry oneself)) were forced to give up (Legendre and Sorace 2003: 214216), since it was evidently in contradiction with the facts: s'éterniser (drag on), s'attarder (linger), se maintenir (keep steady), se pavaner (strut about), se regarder (look at each other) etc. are not telic, but are BE-selecting.

Reflexives cannot belong the domain of the ASH, since it cannot account for them. Some scholars say that it is "a constraint specific to reflexives" but do not specify its nature (Legendre 2007: note 13). One can conclude that, even facing a language with what would be considered gradience by the ASH in terms of auxiliary selection for reflexive verbs, the ASH would use their bivalence (but see note 21) as a reason for excluding them. Even if it did include them, it would not have the adequate means to do so, which means that the ASH's view on auxiliary selection is at best bound to remain partial and ignore a whole domain of auxiliary selection.

\footnotetext{
${ }^{21}$ Moreover, the position of the ASH concerning the valence of reflexives used to justify their exclusion from the field of study is not easy to comprehend: in order to consider reflexives as bivalent (Cennamo and Sorace 2006: 88), the ASH must consider the clitic as an argument and avoid saying that the clitic is a valency-reducing marker since this would make reflexives monovalent verbs (either unaccusatives or unergatives). However the ASH explicitly sides with those who claim that the clitic is a valency reducing marker (Legendre \& Sorace 2003: 216). However, the ASH explicitly sides with those who claim that the clitic is a valencyreducing marker (Legendre and Sorace 2003: 216). Then again, if the ASH considers reflexive verbs monovalent, nothing should prevent them from being treated alongside monovalent non-reflexive verbs and from passing the test of telicity, ASH's primary and most reliable factor.
} 
I think reflexive verbs are concerned with the question of auxiliary selection, and that the explanation must be of the same nature as that put forward for intransitive verbs. I side with those who say that reflexives are fundamentally bivalent, but I consider that this is no obstacle for integrating reflexives into a global explanation (see Giancarli 2011: 156-250). The study of a language such as Corsican, which admits a variation as far as auxiliary selection with reflexive verbs is concerned, can be of great help (see 4.2 below).

3 Scalarity in general as an adequate/inadequate factor to account for auxiliary selection 3.1 Certain syntactic phenomena in context escape any kind of prediction made from a scalar representation

I shall take the example of Corsican, where avè (HAVE) can govern a BE-verb when this verb is either elided or moved away.

\subsubsection{The BE-verb is elided after a servile verb}

In Corsican (as in Italian) there are a number of words that share particular characteristics, i.e. the servile verbs pudè/vulèlduvè (can/want/must), to which I wish to add turnà (start again) and cessàlstancià (stop), in other words three modal verbs and three aspectual ones. They belong to a closed list of oxytonic verbs that share the particularity of being transparent: they can be preceded by either auxiliary. What counts is the chosen verb and the auxiliary that would have been selected if the verb had been conjugated directly. HAVE can be used with a BE-verb (and such a verb would be positioned as BE-selecting on a gradient scale) when the latter is elided after a servile verb. ${ }^{22}$ In case of ellipsis, BE is replaced by HAVE. Let us consider the verbs vultà (come back), campà (live) and andà (go). BE is normally their only possible auxiliary. Yet the following extracts selected HAVE:

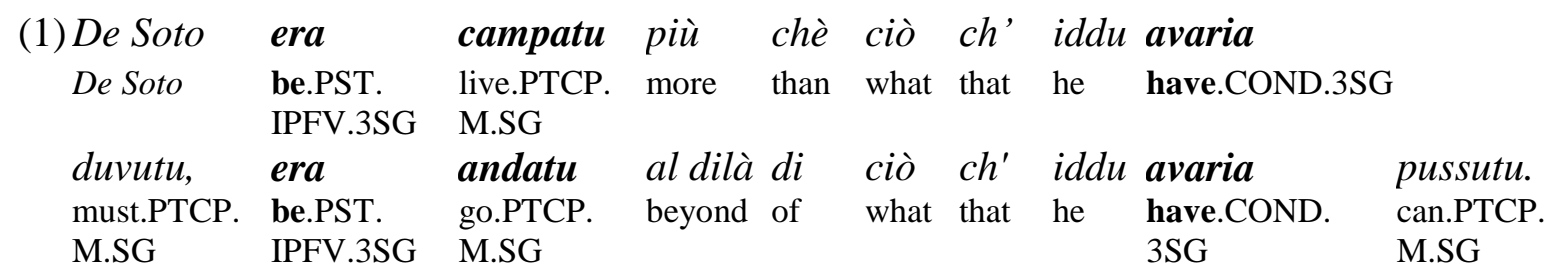

'De Soto had lived longer than he should have, he had gone beyond what he could have.' (SGP)

\footnotetext{
${ }^{22}$ This applies in a low register, because BE can be maintained in a higher register.
} 
(2) $\grave{U} n$ sò quanti, chì si ne eranu andati Not know.PRS.1SG how many who CLIT from there be.PST.IPFV.3PL go.PTCP.M.PL à fà furtuna induv' ellu ci era da chì fà, to make fortune where it there be.PST.IPFV.3SG of what make si ne pentinu $\grave{e}$ dissenu, chì, $s^{\prime}$ elli CLIT of that regret. PST.PFV.3PL and say. PST.PFV.3PL that if they avianu pussutu, eranu vultati. have.PST.IPFV.3PL can.PTCP.M.SG be.PST.IPFV.3PL return.PTCP.M.PL 'I don't know how many, who had gone away to make their fortunes where there was the opportunity, wished they hadn't, and said that, if they could have, they would have returned home.' (AFA)

(1) is a comparative and (2) is a conditional. Both are elliptical structures, corresponding respectively to:

(1') De Soto era campatu più chè ciò ch'iddu avaria De Soto be.PST.IPFV.3SG live.PTCP.M.SG more than what that he have.COND.3SG duvutu campà, era andatu al dilà di ciò ch'iddu must.PTCP.M.SG live be.PST.IPFV.3SG go.PTCP.M.SG beyond of what that he avaria pussutu andà. have.COND.3SG can.PTCP.M.SG go

'De Soto had lived longer than he should have lived, he had gone beyond what he could have gone.'

(2') [...] s'elli avianu

pussutu

vultà, eranu

vultati.

[...] if they have.PST.IPFV.3PL

can.PTCP.M.SG

return, be.PST.IPFV.3PL

return.PTCP.M.PL

'if they could have returned home, they would have returned home.'

In these extracts vultàlcampàlandà select BE, however HAVE is also selected: avianu pussutu, avaria duvutu and avaria pussutu. Why? Because they are 
elliptical forms. With the servile verbs pudèlduvèlvulè (vulè provided it has its must meaning and is consequently BE-selecting), the expected auxiliary is the one normally taken by the verb that follows, i.e. vultàlcampàlandà, thus $\mathrm{BE}$ (for vulè, this is only the case if the verbe is used in the sense of must). The ellipsis of the BE-selecting verbs suppresses the requirement for the expected auxiliary (BE), and HAVE becomes selectable. HAVE is chosen, while a scalar representation would have predicted the selection of BE for these verbs.

The BE-verb does not necessarily have to be elided. Any kind of syntactic structure that moves the BE-selecting verb away will pave the way for the selection of HAVE, as I will now demonstrate.

\subsubsection{The BE-verb is moved away from the servile verb and auxiliary}

This can be done by means of a relative clause, a cleft-sentence, or an apposition. I will limit myself to the relative clause by way of example:

$\begin{array}{lllrl}\text { (3) Petru } & \text { era } & \text { pussutu vultà in stu paesi. } \\ \text { Peter } & \text { be.PST.IPFV.3SG can.PTCP.M.SG return in this village }\end{array}$

'Peter could have gone back to this village.'

(4) Stu paesi, chì vultacci Petru avia pussutu, si chjama Pila-Canali.

This village that go back-there Peter have.PST. can.PTCP. CLIT call.PRS. Pila-Canali.

IPFV.3SG M.SG 3SG

'This village, that Peter could have gone back to, is called Pila-Canale.'

Because vultà is a BE-selecting verb, era (was) is selected in front of the servile verb pudè. However, 4 accepts HAVE because the verb was moved away from the servile verb and from the auxiliary governing it. The reasoning would be the same with a simple inversion:

(3') Avia pussutu Petru vultà in stu paesi.
have.PST.IPFV.3SG can.PTCP.M.SG Peter return in this village
'Peter could have gone back to this village.'

What is common to the two phenomena in 3.1 is that 1) when a BE-verb is elided or moved away that verb loses its capacity to determine the choice of auxiliary. Nevertheless, an auxiliary is necessary. HAVE is then resorted to as a default auxiliary. This shows how vulnerable esse is compared to avè, even in a language that counts more than $350 \mathrm{BE}-$ selecting intransitives. 2) HAVE is 
chosen while a gradient or scalar representation would have forecast the selection of BE.

\subsection{The problem of a crosslinguistic scale}

To set out a wide variety of languages on a single scale, one must either take for granted in accordance with the Null Hypothesis that all the compound forms (all perfects, all pluperfects, etc.) of the languages under consideration are equivalent to each other, or disregard the fact that they are not, whether they be Romance languages or Germanic languages or any other. The problem is that they are not equivalent to each other, and this has to be taken into account. ${ }^{23}$

\subsubsection{All the compound forms (perfects, etc.) of different languages are not equivalent to each other}

All perfects must not be put on the same footing, and this criticism is essential. This claim may be shared by many, but the consequences must also be accepted. For example French passé composé and Corsican passatu quancianu are two compound forms with an auxiliary in the present, both superficially like the English present perfect. However, they should not be carelessly equated with each other because their uses are different; they do not always select the same auxiliary, and I shall go so far as saying that their natures are synchronically different.

The French passé composé can be a temporal anteriority marker (its most common use nowadays: hier il a mangé un gateau / yesterday he has eaten/he ate a cake) or a present perfective i.e. an aspect marker (its initial use in French: il a bien mange / he has eaten well/he has had a good meal). The temporal passé composé is aoristic (like French passé simple il mangea, the only difference being the plane of utterance: passé composé pertains to the plane of discourse and not the plane of historical narrative). It is a past tense that gives a whole view of the event from the outside (unlike French imparfait). The aspectual passé composé on the other hand is not aoristic, and as a

\footnotetext{
${ }^{23}$ The ASH is exposed to this difficulty, and there are only two ways to minimise it: remove certain languages from the scale or, as the ASH does it, set up rules that apply to some languages but not to others (addition of the criterion "internal motion" in Legendre 2007, or "locomotion" in Keller and Sorace 2003). In both cases the cross-linguistic scope of the crosslinguistic scale is reduced.
} 
compound form it is perfective, as opposed to passé simple and imparfait which are simple forms. It capitalises on the resulting state following the change of state, and it is a present form.

French and Corsican choices look identical i.e. an auxiliary in the present followed by a past participle when the examples chosen are present perfective aspectual perfects, as in (5), but let us look at what happens with temporal variants:

(5)Maintenantqu' ils sont arrivés, c'est une autre angoisse.

Avà ch' elli sò gjunti, $\grave{e} u n^{\prime}$ antra angoscia.

Now that they be.PRS.3PL arrived, it is another anxiety

'Now they have arrived, it is another cause for anxiety.' (CDL)

(6) $T u$ es

You be.PRS.2SG

bien arrivé ce soir avec les croisés?

'You did arrive tonight with the crusaders?'

Tù, ghjunghji

sta sera incù $i \quad$ cruciati, ùn hè?

You, arrive.PST.PFV.2SG tonight with the crusaders, not is?

'You arrived tonight with the crusaders, didn't you?' $(\mathrm{H})$

(7) C'est peut-être le même qui rôdait déjà quandmon papa a disparu.

It is perhaps the same that loitered already when my father have.PRS. disappear.

3SG PTCP.M.SG

'It may be the same one [shark] that was already loitering when my father disappeared.'

Ch' ellu ùn sia listessu pesciu chè quand'ellu s' anneì̀ u poverubabbu? cane mo

That he not be.PRS. the same shark as when he CLIT drown. my poor father? SBJV.

3SG

PST.PFV.

$3 S G$

'Could it be the same shark as when my poor father drowned?' (P) 
Examples like (6) and (7) show how different the French "perfect" and the Corsican "perfect" are. They do not match. The French "perfect" can keep its auxiliarised form, while Corsican has to move to a non-auxiliarised aorist form (this is particularly the case for educated or older speakers), since the passatu quancianu is not suitable for narrative contexts or with explicit temporal dates. The difference is that the French "perfect" usually has a temporal past value and sometimes an aspectual perfective one, whereas the Corsican "perfect", even if engaged in an aoristic drift, is basically an aspect. One will easily admit that two semantically different forms cannot appear side by side on the same scale and be identically treated.

Treating them identically nonetheless is one of the main reasons for the difficulties experienced by the ASH since telicity, its primary factor on the gradient whatever the language, faces difficulty in French (cf. 2.1.2), is suited neither to German ${ }^{24}$, nor Corsican (cf. 2.1.2 and 2.1.4) nor Acadian (see 3.2.2) and is challenged by Italian and Dutch (see note 19), just to mention a few languages.

But any scalar representation of auxiliaries in a crosslinguistic perspective would meet difficulties, since positioning the compound forms of different languages on one and the same scale forces one to see them from the same perspective and reduces the differences between them to a quantitative difference. As Mcfadden and Alexiadou (2010) state ${ }^{25}$, the perfect is not a stable and consistent crosslinguitic category, and "two languages will differ in their auxiliary selection at least in part because of the differences in the makeup of their perfects" (390). Taking these differences into account in my analysis of French of France, English, Acadian and Corsican led me in Giancarli (2011) to a different explanation of auxiliary selection than that of the ASH - not a single quantitative explanation but qualitatively different explanations for each language considered. I shall limit myself here to giving an overview of auxiliary selection in Acadian before providing a non-scalar representation of auxiliaries in Corsican.

\subsubsection{The example of Acadian French: a language whose "perfect's" double nature is directly correlated with auxiliary selection}

A model that would only take into account the morphology of the French perfect and ignore its double nature, as would any scale, would hardly be in a

\footnotetext{
${ }^{24}$ The ASH itself had to give up telicity as its number-one criterion for German (Keller and Sorace 2003).

25 These authors build on the difference between the perfect of result and all the others (in particular the experiential perfect, but including also the perfect of result) in Earlier English to explain the choice of be or have, respectively (420-421).
} 
position to incorporate a language whose choice of auxiliary would rely on the French "perfect's" double nature. Such a language exists, since in Acadian one single intransitive verb will be (using the unaccusative/unergative terminology) unaccusative when in the aspectual perfect, and unergative when in the temporal "perfect", and will therefore select the BE or HAVE auxiliary on that basis. At least 10 verbs can undoubtedly select BE in Acadian: aller, arriver, descendre, monter, mourir, partir, passer, rentrer (entrer is not so common), sortir, venir/menir. ${ }^{26}$ I shall take partir (leave) for illustrative purposes. The same speaker ${ }^{27}$ uses the same verb partir in (8) and in (9):

(8)J'ai sauvéuneprincesse,pis $i$ dit, je sus obligé $d$ 'alleravec sous peine de mort, I saved a princess then he says I am obliged to go with on pain of death $i$ dit,ielle est partie asteur,j'ai été trahi hesaysshe be.PRS.3SG leave.PTCP.F.SG now I have been betrayed 'She has left now.'

(9) On avaitpas soupé quand qu'on a parti, pis We had ' $\mathrm{nt}$ had dinner when we have.PRS.3SG leave.PTCP.M.SG then c' est la faim qui nous a fessé it is hunger that us struck 'We hadn't had dinner when we left, then we were hunger stricken.'

In 9 the "perfect" is temporal and aoristic: it marks the event as past, located as disconnected from the origin situation, in a temporal adverbial clause introduced by the conjunction quand que (when that/when). Because the "perfect" is of a temporal nature, auxiliary selection is made in favour of HAVE: quand qu'on a parti.

In 8 on the other hand, the perfect is of an aspectual nature and, as a compound form, it refers to a perfective value: the link with the situation of uttering is demonstrated by the presence of the deictic adverb asteure (now). Ielle est partie asteur is about a third person's absence from the enunciative space. You could add an aspectual quantifier like depuis trois semaines (for three weeks) to underline this point: ielle est partie depuis trois semaines,

${ }^{26}$ Respectively go, arrive/succeed/happen, go down, go up, die, leave, pass/become, go in/come back, get out, come.

${ }^{27}$ This speaker is one of seven informants recorded while telling a tale and living in southeast Brunswick, Canada. 
which is synonymous with ielle est absente depuis trois semaines: because partir is discrete ${ }^{28}$, the temporal adjunct depuis trois semaines does not quantify the verb but the state resulting from the process i.e. the fact of not being there. Because this perfect is aspectual, auxiliary selection is made in favour of BE.

FF and Acadian French have the same opposition between two "perfects": a temporal anteriority "perfect" and an aspectual present perfective perfect. However, in FF the aspectual perfect is compatible with HAVE as well as with BE, as was shown by extract 5 , while in Acadian the aspectual perfect only selects BE. And while in FF the temporal "perfect" is compatible with HAVE and BE, as was shown by extracts 6 and 7, in Acadian the temporal "perfect" only selects HAVE. In FF this dichotomy between the temporal "perfect" and the aspectual perfect transcends the difference between BE and HAVE, so that the explanation for auxiliary variation must be sought elsewhere ${ }^{29}$. It must not be sought elsewhere in Acadian, however, which builds on the double nature of its "perfect" and establishes a correlation between the kind of "perfect" and the choice of the auxiliary. Listing Acadian verbs on a variation scale looking only at the verb itself would not account for a dimension of variation based not on the verb but on a pair of values attached to the compound form.

\section{A non-scalar representation of Corsican auxiliaries}

Corsican selects HAVE with its non-reflexive verbs when they are bivalent and BE with at least 350 of its monovalents. In the reflexive domain, certain types of reflexive verbs, unlike French or Italian, admit either BE or HAVE. Here are examples of an intransitive with HAVE (10), one with BE (11), two examples of variation with an intransitive (1 compared to 4, 12 compared to 13) and two with a reflexive (14 and 15):

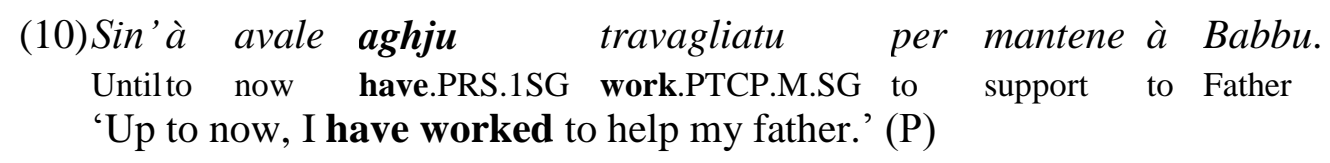

\footnotetext{
${ }^{28}$ We speak of a discrete process when it can be individuated as an occurrence that manifests a quantitative delimitation of the notion, a dense process when neither the quantitative nor qualitative dimension is prevalent; while compact applies to what is indivisible in the strictest sense and open at both ends (Culioli 1991-92: 12).

${ }^{29}$ See Giancarli 2011: 94 ff.
} 
(11) Elli ci sò sfilati à millaie sott' à l'ochji. Them there be.PRS.3PL parade.PTCP.M.PL by thousands under to the eyes 'They paraded by the thousands before our eyes.' (ABM)

(1)De Soto era campatu più chè ciò ch' iddu avaria De Soto be.PST. live.PTCP. more than what that he have.COND.3SG $\begin{array}{lllllll} & \text { IPFV.3SG } & \text { M.SG } & & & \\ \text { duvutu, } & \text { era } & \text { andatu al dilà di ciò } c h ' \text { iddu avaria pussutu. }\end{array}$ must.PTCP. be.PST. go.PTCP. beyond of what that he have.COND. can.PTCP. M.SG IPFV.3SG M.SG 3SG M.SG 'De Soto had lived longer than he should have, he had gone beyond what he could have.' (SGP)

(4) Stu paesi, chìvultacci Petru avia pussutu, si chjama Pila-Canali. This village that go back-there Peter have.PST. can.PTCP. CLIT call.PRS. Pila-Canali. IPFV.3SG M.SG 3SG

'This village, that Peter could have gone back to, is called Pila-Canale.'

(12)Bulà, aghju bulatu un pocu inghjilocu è agiograffia, hè virità, Fly have.PRS.1SG fly.PTCP.M.SG a little everywhere and geography itistruth $m$ ' hè ghjuvata assai. to me be.PRS.3SG be useful.PTCP.F.SG much

'I have flown a little everywhere, and geography, that's correct, served me a lot.' (PP)

(13) H̀̀ vulatu à pezzi.

It be.PRS.3SG fly.PTCP.M.SG to pieces

'It was shattered to pieces.'

(14) Microcosimuи paese? Ben intesu, a dritta è a manca, $i$ neri è $i$ rossi, Microcosm the village? Well heard the right and the left the black and the red dui partiti chìsi sò spartuti una cintunara d' elettori, two parties that CLIT be.PRS.3PL share.PTCP.M.PL a hundred or so of voters cuntendu $i$ braganati. counting the multicoloured 'Is the village a microcosm? Of course, the right and the left, the black and the red, two parties that shared among each other about a hundred voters, including the multicoloured ones.' (DF) 
(15)- "Alora, spartaremmu $i$ vacchi, avali!" - "Seti vo! Seti vo!"

- "Then share.FUT.1PL the cows now!" - "You are you! You are you!

S' hani spartutu i vacchi,dici alora: "Qualissi voli?"

CLIT have.PRS.3PL share.PTCP.M.SG the cows he says then: "Which you want?"

"- "Then we'll share the cows, now!" - "Up to you! Up to you!" They shared the cows, then he says "Which ones do you want?"” (CS)

Each of these illustrative extracts will be given an explanation in this article.

\subsection{Intransitive verbs}

\subsubsection{Definitions of Source and Goal}

I call Source and Goal thematic macro-roles, encompassing the roles of agent and patient. I argue that in Corsican HAVE is selected when the subject corresponds to a Source, an acting role, while BE is selected when the subject corresponds to both a Source and a Goal, acting and acted upon, so it satisfies two thematic roles. This applies to simple (non-reflexive) BEselecting verbs, whose subject has this dual status intrinsically, and to BE-selecting reflexive ones, whose subject satisfies this dual status either intrinsically or (most of the time) obtains it by means of a co-reference.

What comes under the terms Source and Goal? Source and Goal are macro-roles. Each macro-role is accompanied by a distinction between several levels, but a hierarchy between those levels, though easy to draw, is not necessary, ${ }^{30}$

30 This is unlike Van Valin's macro-roles "Actor" and "Undergoer" (Van Valin 1990; Van Valin and Lapolla 1997) which are organised in a relevant gradient hierarchy. Secondly, theirs are two discrete categories, to which each argument does or does not belong, thus excluding double membership, Thirdly our macro-roles are also chosen to comply as nearly as possible with the semantic realisations of the arguments actually found in the range of both intransitive and reflexive constructions. 
since the selection of HAVE requires the activation of only one macro-role (Source) and the selection of $\mathrm{BE}$ is justified as long as the two macro-roles are involved, whatever the particular roles within the macro-roles. It is of no importance whether the subject is positioned at the top or at the bottom of a Goal hierarchy, what counts is that it is recognised as bearing any role encompassed within that macro-role. A scalar view, and a fortiori a gradient one with one (or more) core(s) and one (or more) periphery/ies, is consequently irrelevant.

The Source has the primitive properties of an agent rather than a patient, of a cause rather than a consequence, but Source is not confined to agent, and Goal is not reducible to patient: a Source is the instigator of a process for which it is responsible. It encompasses the semantic roles of agent, instrument or stimulus source of a perception or knowledge necessarily pre-existing this perception or knowledge. A Goal is an affected argument in the sense that it undergoes a change of state, with at least one of its properties being the case before the change of state but not after. It can be a locative, i.e. an inanimate argument affected by a state; an experiencer, i.e. an animate argument affected by a state; a theme, i.e. a subject argument whose localisation is predicated by a state verb; a patient affected by a change of state; a beneficiary, or a recipient.

Source and Goal will be useful to us in the following way: with Corsican simple (nonreflexive) verbs, avè (HAVE) will be selected when the subject has the Source macro-role, and esse (BE) when it is both Source and Goal. Three categories will be distinguished: process verbs with no variation, process verbs with variation and state verbs:

\subsubsection{Discrete and dense process verbs with no variation: when the subject is an agent- Source, and a patient-Goal}

This has to do with two cases: firstly when the subject is an agent-Source, and a patientGoal, which will concern discrete and dense process verbs. Secondly when the subject is an agent-Source, and a locative-Goal, which will concern weather verbs (dense). I shall only present the first one here; for an illustration of the weather verbs see Giancarli (2011: $123 \mathrm{ff}$.). 
When this dual-status argument is both an agent-Source and a patient-Goal, it triggers a process that affects an argument that happens to be itself. It is an agent-patient affected by the resulting state; it initiates a process but undergoes it at the same time. This view encompasses not only the subclass of verbs that some would call telic and that select BE both in Corsican and in their French equivalents, ${ }^{31}$ but also verbs of movement. ${ }^{32}$ Corsican verbs of movement select BE like the verbs of change of place because they are not based on the criterion of telicity but on the dual status agent-patient, and this requirement is met:

(11) Elli ci sò sfilati à millaie sott' à l'ochji.

Them there be.PRS.3PL parade.PTCP.M.PL by thousands under to the eyes

'They paraded by the thousands before our eyes.' (ABM)

$\begin{array}{llllll}\begin{array}{l}\text { (16) Sò } \\ \text { be.PRS.1SG }\end{array} & \text { corsu } & \text { à mettemi } & \text { à } & u \text { pianò. } \\ \text { 'I hurried to get to my piano.' (BC) } & \text { to put myself } & \text { to } & \text { the piano }\end{array}$

This reminds one of the middle voice, by which the subject "effectue en s'affectant" [effects while being affected], "effectue quelque chose qui s'accomplit en lui" [achieves something which is being achieved in him] (Benveniste 1974: 173).

\subsubsection{Discrete and dense process verbs that admit either one or the other auxiliary}

Some verbs, less than a dozen according to my countings, admit either one or the other auxiliary and select BE 1) when the subject is both a Source and an inanimate Goal, 2) when it is both a Source and an animate non-volitional

\footnotetext{
${ }^{31}$ Nascelnaître (be born), more/mourir (die), diventà/devenir (become), etc.

${ }^{32}$ Corre (run), girà (move, circulate), sfilà (parade), etc.
} 
Goal, or 3) when it is both a Source and an animate non-controller Goal. I shall here provide a few illustrations of 1) here:

1) Corre, saltà, vulà (run-jump-fly respectively): the subject is both a Source and an animate agentive Goal (HAVE) / the subject is both a Source and an inanimate Goal (BE).

Corre, saltà, vulà can select either BE or HAVE: BE when their subject is both a Source and a Goal. They select HAVE when the subject is animate and agentive, and BE when it is inanimate. Because the subject of a BE-selecting verb involves an undergoing dimension, there is a distribution on the following basis: the verb takes BE when the subject is inanimate (and therefore unagentive), which makes the Goal component prevalent, and complementarily HAVE is selected when the subject is animate and agentive, which makes the Source component prevalent. Hence the following contrast between 12 and 13 with the verb vulà:

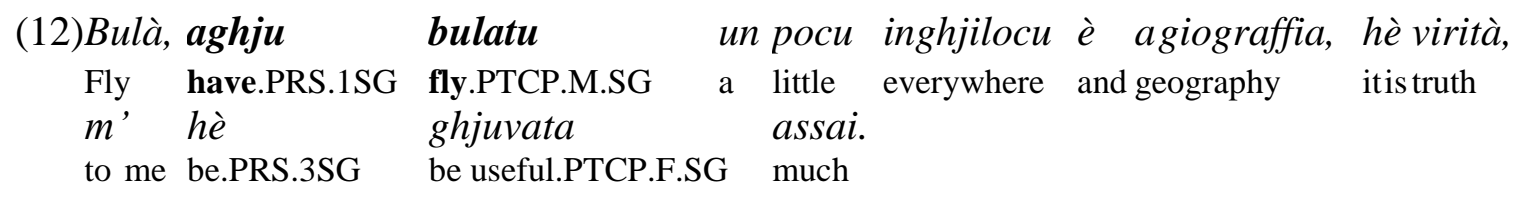

'I have flown a little everywhere, and geography, that's correct, served me a lot.' (PP)
(13) Hè vulatu à pezzi.
It be.PRS.3SG fly.PTCP.M.SG to pieces
'It was shattered to pieces.'

Vulà takes HAVE in 12 with a first-person animate subject and has its literal sense (here fly in the air aboard a plane), but it takes $\mathrm{BE}$ when its subject is inanimate, with a figurative sense, in 13 to be shattered, not fly but fly into pieces.

\subsubsection{Compact verbs}

I will now try to show the reason why Corsican compact verbs can select BE, namely when the subject is both a stimulus-Source and a patient-Goal, to be more precise, a Goal because it undergoes an assessment/evaluation. A certain number of Corsican BE verbs, inexplicable by telicity since, as states, they present no 
change of state, change of place, or movement, can find an explanation through the SourceGoal duality. ${ }^{33}$ Here are a few examples from our corpus:

(17)Sò campatu assai cù e parsone maiò.

be.PRS.1SG live.PTCP.M.SG much with the people big

'I have lived a great deal among grown-ups.' (PP)

(18) $S t^{\prime}$ arburu, vai puru, da nulla ci hè ghjuvatu.

This tree, decidedly, of nothing to us be.PRS.3SG be good.PTCP.M.SG

'Decidedly this tree will have been of no use to us.' (EAG)

(19)Misaria piaciutu à principià ista storia cum' elle principianu

Mebe.COND.3SG please.PTCP.M.SG to begin this story as they begin

e fole. Mi saria piaciutu à dì :

the fairy tales Me be.COND.3SG please.PTCP.M.SG to say:

'It would have pleased me to begin this story in the manner fairy tales begin. It would have pleased me to say:' (PP)

They are state verbs, intransitive and unpassivizable. As state verbs, their subject is nonagentive by definition, so it cannot be viewed as partly patient and partly agent, thus excluding any interpretation in terms of middle voice. This will not stop us from claiming that their subject has a dual status, both Source as a stimulus (source of the perception/feeling/cognition of an experiencer) and Goal as a patient, insofar as it undergoes an evaluation. For example with ghjuvà (be useful) the subject is Source of the perception of the object qualified as good, and patient of an evaluation which makes it qualified as such.

\footnotetext{
33 The verbs concerned are: bastà (be sufficient), bisugnà (be necessary), calzà (be suitable), campà (live), cunfà (be fit), cunvene (be convenient), custà (cost), dispiace (displease), durà (last), esiste (exist), esse (be), garbà (be enjoyable), ghjuvà (be good, be useful), mancà (be lacking), occorre (be convenient), parè (appear), piace (please), scunvene (not be convenient), spiace (displease), stà (be, stay), vive (live), valè (be worth), vulè (be necessary), sembrà (seem).
} 
When I say "evaluation/assessment", the term is four-fold:

- It can be a root modality (Culioli's modality $n^{\circ} 4^{34}$ ), enabling the speaker to assess how autonomous the subject is. The verbs concerned are occorre and bisugnà. The very common verb vulè also means be necessary when $\mathrm{BE}$ is selected, but it experiences an interesting variation (cf. Giancarli 2011: 140).

- It can take the form of a qualitative evaluation by the speaker, a value judgment on the grammatical subject passed with a positive or negative valuation (modality $n^{\circ} 3$ ). The verbs concerned are ghjuvà, calzà, cunfà, cunvene, scunvene, garbà, piace, spiace, dispiace.

- It can be a quantative evaluation of the subject by the speaker, in the case of durà, custà and valè which are all indicative of how big/tall/long/expensive the referent of the subject is in other words its quantitative dimension.

- Finally, it can be a superimposition of the last two evaluations: firstly with bastà and mancà with which the speaker passes judgment on a quantity assigned to the subject. Secondly with parè and sembrà which, on top of a qualitative evaluation, involve a quantitative evaluation through the epistemic modality they carry (modality $n^{\circ} 2$ ). They enable the speaker to modulate the strength of his/her assertion by giving it a degree of assertability that quantifies how probable the relationship between the subject and the predicate is.

As for the verbs of existence (esse, stà, vive, esiste, campà, to which parè and sembrà can be added), they lend themselves to a quantitative or qualitative evaluation according to the context (see Giancarli 2011: 134 ff.).

\subsection{Reflexive verbs}

\subsubsection{The types of reflexive verbs that admit variation, either one or the other auxiliary}

\subsubsection{Presentation}

Corsican reflexives are composed of a clitic personal pronoun (CLIT), pre-verbal in the finite forms and post-verbal the rest of the time. It is identical to the

\footnotetext{
${ }^{34}$ Type 4 modality concerns the relation between the grammatical subject and the predicate, type 3 modality is a qualifying modality concerned with judgments about the content of the predicative relation, type 2 modality establishes a relation between the enunciator and the propositional content and assesses the (im)probability of the validation of the relation (Culioli 1990 and 1999).
} 
non-reflexive accusative pronoun in all the persons $(\mathrm{mi} / \mathrm{ti} / \mathrm{ci} / \mathrm{vi})$ except the third person in the plural and singular, where it has the special form si. They are not limited to BE as is the case in French or Italian; they can select either BE or HAVE. Ten kinds of reflexive verbs can be distinguished in Corsican, bivalent or monovalent:

Case 1: true reflexive
(20)Petru si h̀̀
lavatu.
Peter CLIT be.PRS.3SG wash.PTCP.M.SG
'Peter has had a wash.'

Case 2: true reflexive of inalienable possession
(21) Petru si h̀̀
Lavatu
i capelli.
Peter CLIT be.PRS.3SG
wash.PTCP.M.SG the hair
(21') Petru si
Peter
hà
lavatu
i capelli.
'Peter washed his hair.'

Case 3a: ethic reflexive of alienable possession with a bivalent verb
(22) Petrusi h̀̀ cumpratu una vittura.
Peter CLIT be.PRS.3SG
buy.PTCP.M.SG a car
(22')Petrusi hà
cumpratu una vittura.
Peter CLIT have.PRS.3SG buy.PTCP.M.SG a car
'Peter bought a car.'

Case 3b: ethic reflexive with a monovalent verb
(23) Petru si
h̀̀
fermu
quì.
Peter CLIT be.PRS.3SG stay.PTCP.M.SG here
'Peter stayed here.'

Case 4a: reciprocal reflexive without an object
(24)Petru è
Paulu si
sò
azzuffati.
Peter and Paul CLIT be.PRS.3PL fight.PTCP.M.PL
'Peter and Paul fought.'

Case 4b: reciprocal reflexive with an object
(25) I zitelli si
sò
spartuti
e cubi.
The children CLIT be.PRS.3PL share.PTCP.M.PL the marbles
(25')I zitelli s' anu spartutu e cubi.
The children CLIT have.PRS.3PL share.PTCP.M.SG the marbles
'The children shared the marbles.' 
Case 5: inherent reflexive

(26) Una turista taliana si h̀̀ svanita.

A tourist Italian CLIT be.PRS.3SG faint.PTCP.F.SG

'An Italian tourist has fainted.'

Case 6: medio-passive reflexive

(27)Petru si h̀̀ avanzatu.

Peter CLIT be.PRS.3SG move forward.PTCP.M.SG

'Peter moved forward.'

Case 7a: reflexive with a passive meaning with a bivalent verb

(28) E ghjembe si sò tronche ${ }^{35}$.

The branches CLIT be.PRS.3PL break.PTCP.F.PL

'The branches have broken.'

Case 7b: with a monovalent verb, where a distinction must be made between 29 and 30:

(29) $\mathrm{Si}$ hì / hà travagliatu.

CLIT be.PRS.3SG / have.PRS.3SG work.PTCP.M.SG

'One has worked.'

(30) $\mathrm{Si}$ h̀ andati.

CLIT be.PRS.3SG leave.PTCP.M.PL

'One has left.'

However, it is not just any kind of reflexive that accepts variation: of the ten listed, six must select BE (cases 1, 3b, 4a, 5, 6, 7a), and four need not select BE exclusively and can therefore select HAVE as well (cases 2, 3a, 4b, and possibly some monovalents of 7b).

35 The reflexive $e$ ghjembe si sò tronche should not be confused with the (non-reflexive) anticausative (e ghjembe hanu troncu, literally the branches have broken). They differ in terms of productivity, relationship with a transitive counterpart and, most importantly, presence/absence of a cause: if an anticausative presents a process occurring without a cause (Reinhart 2002, Härtl 2003, Talmy 2003, Reinhart and Siloni 2005, Kallulli 2006, etc.), e ghjembe hanu troncu (the branches have broken) is an anticausative, but Corsican reflexive $e$ ghjembe si sò tronche is not, since a secondary Source is present; see 4.2 2. 


\subsubsection{Reasons for the variation with reflexive verbs: valency and orientation. Subject- orientation (BE) / object-orientation (HAVE)}

What do BE-selectable reflexive verbs have in common? If case $7 \mathrm{~b}$ were disregarded, the answer would be: bivalence and the explicit presence of an object. Or perhaps one part of $7 \mathrm{~b}$ can be included in the explanation, the one illustrated by si hè/hà travagliatu (one has worked). Of course there is neither bivalence nor an object here, since the verbs are monovalent (they are unergatives); however I think they can be attributed the same functioning as the bivalent forms $2-3 \mathrm{a}-4 \mathrm{~b}$, thanks to the internal object:

Unlike unaccusatives, whose monovalence is undisputable, unergatives globalise the process by integrating features that could be rendered by complements, the complement is "incorporated" (Hale and Keyser 2002). Herslund (1996) even claims that unergatives are bivalents in the guise of monovalents. They have an object, but instead of externalising it in the form of a NP after the verb, it is lexicalised inside the verb root; we usually call this an internal object. Travaglià can be glossed as do some work i.e. produce some work through working, parlà by produce some speech through speaking, and so on. Showing the deep similarities that monovalent unergatives have with bivalents is a way of justifying the possible selection of HAVE with unergatives in $7 \mathrm{~b}$. I claim that the series of reflexives that has an object (internal object included) is also the one open to the selection of HAVE, while the series without an object is restricted to BE. The choice of auxiliary thus has something to do with valency.

Unfortunately, the criterion of valency shows its limits, since the presence of an object argument makes the selection of HAVE possible but not compulsory due to the fact that BE remains selectable (remember 21, 22, 25 and 29). We are now facing another auxiliary variation, but with an equal number of arguments. To understand this variation within the Corsican reflexive construction, it is necessary to turn to a complementary explanation, namely the orientation.

The criterion of orientation (or in more general terms topicalisation ${ }^{36}$ ) helps one understand how the selection is made under certain conditions. In bivalent constructions, the auxiliaries are the markers of different orientations: BE towards the subject, HAVE towards the object. The sentence will be oriented towards one of the arguments, and will say something about the state it is in.

\footnotetext{
36 This refers to the phenomenon in which some element is singled out as the topic: "An entity, $\mathrm{E}$, is the topic of a sentence, $\mathrm{S}$, iff in using $\mathrm{S}$ the speaker intends to increase the addressee's knowledge about, request information about, or otherwise get the addressee to act with respect to E" (Gundel 1988: 210).
} 
This criterion is relevant only when the speaker faces a choice in terms of auxiliary, i.e. with reflexives including an object, which I referred to as cases $2,3 \mathrm{a}$ and $4 \mathrm{~b}$ above. Here are a couple of examples of reciprocal reflexives with an object (case 4b) showing variation of the same verb sparte (share), conjugated with BE in 14 and HAVE in 15:

(14) Microcosimuи paese? Ben intesu, a dritta è a manca, $i$ neri è $i$ rossi, Microcosm the village? Well heard the right and the left the black and the red dui partiti chì si sò spartuti una cintunara d' elettori, two parties that CLIT be.PRS.3PL share.PTCP.M.PL a hundred or so of voters cuntendu $i$ braganati. counting the multicoloured

'Is the village a microcosm? Of course, the right and the left, the black and the red, two parties that shared among each other about a hundred voters, including the multicoloured ones.' (DF)

(15)- "Alora, spartaremmu $i$ vacchi, avali!" - "Seti vo! Seti vo!"

- "Then share.FUT.1PL the cows now!" - "You are you! You are you!

S' hani spartutu i vacchi, dici alora: "Qualissi voli?"

CLIT have.PRS.3PL share.PTCP.M.SG the cows he says then: "Which you want?"

"- "Then we'll share the cows, now!" - "Up to you! Up to you!" They shared the cows, then he says "Which ones do you want?"” (CS)

In 14, sparte is associated with BE, which highlights the prevailing role of the political parties on the island, while the electors are presented as disposable and insignificant, mere puppets in the hands of the elected officials that enable them to become powerful local leaders. HAVE (dui partiti chì s'anu spartutu una cintunara d'elettori) would have given the electors an autonomous dimension out of the subject's control, inadequate in the local context.

In 15 three brothers cannot fairly share the family cows, after one of them cheated the others with the corn and wine. The cows are the third object to be shared on the list, and everyone is very careful about the last share. I vacchi in s'hani spartutu $i$ vacchi is the main element of the sentence around which the discourse is centred, and it is also the topic of the question Qualissi voli ? / which ones do you want? 
Conversely, the choice of BE would have been subject-centred, and would have presented the collective subject as a block, as if they were acting by common consent in full agreement without making the cows (grammatical object) an issue.

As for si hè travagliatu/si hà travagliatu (the unergative of case $7 \mathrm{~b}$ ), the acceptability of HAVE is understandable on the basis of what was said previously in terms of valency. Unergatives internalise a bivalent relationship inside the verb root through an internal object, so they do have an object. The idea of an internal object is useful in terms of valency when it brings the monovalent unergatives back to bivalents. But within the context of a choice between BE and HAVE based on orientation it is useless, since I cannot claim that HAVE is still the marker of an object-orientation, considering there is no autonomous object in itself.

\subsection{2 $\mathrm{Si}$ is an argument (Source), and the subject has a dual status Goal + Source}

I claim that the pronoun $s i$ is an argument (a deficient argument but nevertheless an argument ${ }^{37}$ ) to which the thematic role of Source is assigned. Apart from one exception (the monovalent unergative), the clitic pronoun faces a subject endowed with a dual status Goal + Source. ${ }^{38}$ The dual status of the subject is the reason for the selection of BE with reflexive Corsican verbs ${ }^{39}$, except in one case: the reflexive with a passive meaning with a monovalent unergative. This position needs justifying, as there is no consensus on the matter:

For some scholars, the clitic is not an argument, but a valency-reducing marker, that suppresses an argument and leads to a monovalent construction (which I call View 1). According to the first version of View 1, si absorbs the internal argument, which leaves the subject as the sole remaining argument, an external argument (Source), and the verb is a monovalent unergative - the

$37 \mathrm{Si}$ (with both monovalent and bivalent reflexives) cannot be conjoined with a lexical subject, it is not quantifiable, not qualifiable, not suffixable, not cleavable, hardly dislocable, and not stressable. It must be in contact with the verb/auxiliary, and to the left of the verb/auxiliary in finite assertive forms.

38 This dual status is obtained either by means of a co-reference (most of the time), or the subject has it intrinsically (see Giancarli 2011: chapter 4 for more detailed discussion).

${ }^{39}$ At least as a primary reason, because we must remember that Corsican reflexives accept auxiliary variation: they select BE only if in the first stage the subject has a dual status, and if in the second stage the reflexive is bivalent + subject-oriented, since complementarily HAVE is an object-orientation marker. 
opposite of a passive construction. Reflexives would be valency-reducing markers by means of absorption of the Goal argument, making the verb intransitive. This is View 1a, supported by Alexiadou and Anagnostopoulou (2004) and Reinhart and Siloni (2005).

This view is not sustainable. For example, it is at odds with the predictable choice of auxiliary: if the only argument left is the Source of a verb considered unergative, it is the auxiliary HAVE that should govern the reflexive (unless reflexives are a separate case completely disconnected from non-reflexive intransitives and any hope of a global explanation is abandoned), but BE is the only possible auxiliary in Italian or French, and either HAVE or BE is selected in Corsican. Moreover this view obviously does not apply to a language such as Corsican whose reflexives accept monovalents (cf. 23 Petru si hè fermu quì, Petru is stayed here) and are therefore not derivable from a bivalent structure. This capacity rules out any approach in terms of absorption, whether an absorption of the Goal argument or of the Source argument ${ }^{40}$ since there is no transitive to be turned into an intransitive.

According to other scholars, si suppresses the external argument, which leaves the subject as the sole remaining argument, an internal argument, and the verb is a monovalent unaccusative, similar to a passive construction. This is View 1b, supported by Burzio (1986), Legendre and Sorace (2003) and Cennamo and Sorace (2006). This view is not sustainable either - firstly, because languages such as Corsican have reflexives that accept monovalents and secondly because in Corsican, Italian or French (to name but a few), if the clitic was used when the Source is not present, one would also expect it to appear also when the passive is lacking a Source, i.e. an agent, but this never happens:

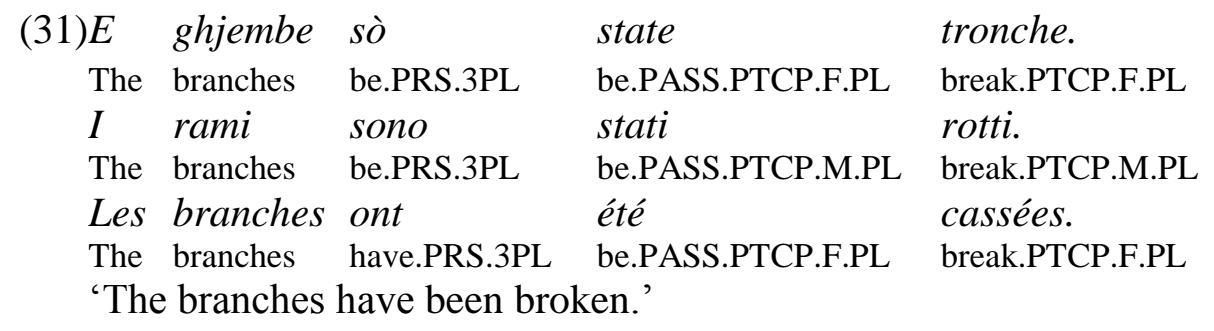

\footnotetext{
${ }^{40}$ See Giancarli (2011: 183-185) for reasons arguing against View 1a in other languages too, even when their reflexive construction is limited to bivalent verbs.
} 


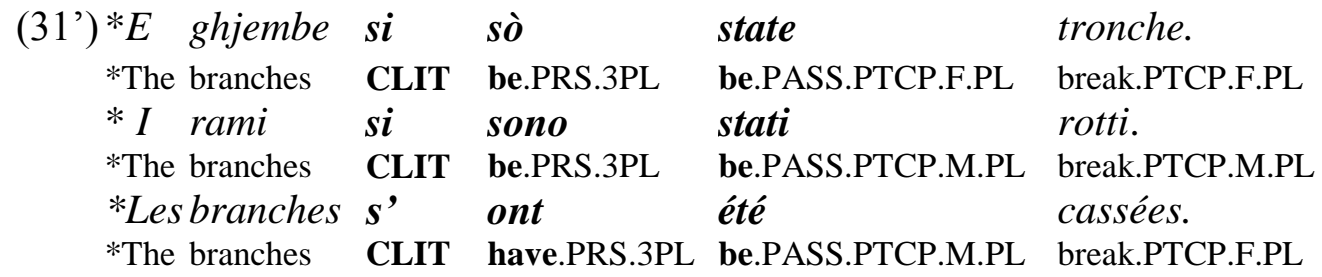

The Corsican, Italian and French sequences above are ungrammatical because the clitic pronoun itself already instanciates a Source argument.

Another position holds that the clitic is an argument (which I call View 2) placed within the valency of the verb, whether monovalent or bivalent. According to one version of View 2, which I call View 2a, it is an internal argument, while the subject would be the external argument. This is supported by Rizzi (1986) in Italian and Dobrovie-Sorin (1998) in Roman languages in general. Alternatively, it is an external argument, while the subject would be the internal argument. This is View 2b, supported by Kayne (1988) or Embick (2004) in Roman languages, and which is the closest to View 2c I shall put forward.

I share with View $2 \mathrm{~b}$ the idea that $s i$ is a Source argument. Because si is a Source argument, the sentence containing it is not compatible with the presence of an agent (Source), even when the reflexive construction sounds similar to a passive, while a passive is compatible with an agent:

(28) E ghjembe si sò tronche.

The branches CLIT be.PRS.3PL break.PTCP.F.PL

'The branches have broken (themselves).'

(28') *E ghjembe si sò tronche da Petru / da u ventu.

*The branches CLIT be.PRS.3PL break.PTCP.F.PL by Peter / by the wind

*'The branches have broken by Peter / by the wind.'

(31) E ghjembe sò state tronche.

The branches be.PRS.3PL be.PASS.PTCP.F.PL break.PTCP.F.PL

'The branches have been broken.'

(31') E ghjembe sò state tronche da Petru / da u ventu.

The branches be.PRS.3PL be.PASS.PTCP.F.PL break.PTCP.F.PL by Peter / by the wind 'The branches have been broken by Peter / by the wind.' 
(20) Petru si hè lavatu.

Peter CLIT be.PRS.3SG wash.PTCP.M.SG

'Peter has had a wash.'

(20’)*Petru si hè lavatu da Petru.

*Peter CLIT be.PRS.3SG wash.PTCP.M.SG by Peter

*'Peter has had a wash by Peter.'

(32) Petru hè lavatu.

Peter be.PRS.3SG wash.PTCP.M.SG

'Peter is washed.'

(32')Petru hè lavatu da Petru.

Peter be.PRS.3SG wash.PTCP.M.SG by Peter

'Peter is washed by Peter.'

(24) Petru è Paulu si sò azzuffati.

Peter and Paul CLIT be.PRS.3PL fight.PTCP.M.PL

'Peter and Paul fought.'

(24')*Petru è Paulu si sò azzuffati da Ghjuvanni.

*Peter and Paul CLIT be.PRS.3PL fight.PTCP.M.PL by John

*'Peter and Paul fought by John.'

(33) Petru è Paulu sò stati azzuffati.

Peter and Paul be.PRS.3PL be.PASS.PTCP.M.PL fight.PTCP.M.PL

'Peter and Paul have been beaten.'

(33')Petru è Paulu sò stati azzuffati da Ghjuvanni.

Peter and Paul be.PRS.3PL be.PASS.PTCP.M.PL fight.PTCP.M.PL by John

'Peter and Paul have been beaten by John.'

$\mathrm{Si}$ is an argument to which the thematic role of Source is assigned (as in View 2b), but the subject is not a Goal argument. I disagree with Views $2 \mathrm{a}$ and $2 \mathrm{~b}$ on 
the three following issues and for the following reaons: 1) within the reflexive with a passive meaning a distinction must be made between two levels of Source. 2) Si and the subject are co-referential. It is because $s i$ is a Source argument and because si and the subject are coreferential that the subject is not only a Goal argument. Hence my third point: 3) I see si as a Source argument (a deficient argument) but that does not mean the subject is a Goal argument, since the subject has a double status of Goal + Source, due to the co-reference. This double status is the reason for the selection of $\mathrm{BE}$ in the Corsican reflexive construction (provided the criteria of valency and orientation do not modify this choice). The subject of a passive construction is a Goal argument, but it is because the subject of a reflexive construction is not simply a Goal argument (unlike View 2b) that the clitic is unacceptable in a passive:

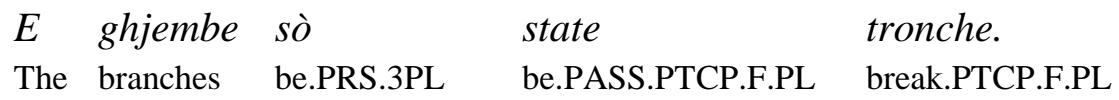

'The branches have been broken.'

$\left(31^{\prime}\right) * E$ ghjembe si sò tronche.

*The branches CLIT be.PRS.3PL be.PASS.PTCP.F.PL break.PTCP.F.PL

In a passive, the subject must be a Goal argument only. Our position can be called View $1 \mathrm{c}$ and summarized in the following way: si is a Source argument while the subject (Goal argument) is assigned the complementary thematic role by means of a co-referential relationship with the clitic pronoun ${ }^{41}$ and therefore a dual status of Goal + Source, hence the selection of BE. I shall provide a few illustrations with commentaries:

True reflexive (case 1):

$\begin{array}{cll}\text { (20) Petru si h̀̀ } & \text { lavatu. } \\ \text { Peter CLIT be.PRS.3SG } & \text { wash.PTCP.M.SG } \\ \text { 'Peter has had a wash.' } & \end{array}$

The clitic pronoun and the subject are co-referential. The clitic is an animate Source argument (Source in the sense of an agent), and the subject is both a Goal argument (Goal in the sense of a patient) intrinsically + a Source argument by means of its co-reference with the clitic. There are two arguments (the

${ }^{41}$ For the sake of simplicity I leave out the Corsican variant si hè troncu ghjembe (see Giancarli 2011: 225 ff.). 
subject and the clitic) corresponding to one actor. Petru si hè lavatu can be glossed by si has washed Petru, with a locating relation of identification between the subject and the clitic: Petru (the Goal argument) is washed but is also the washer, and the dual status of the subject $(\mathrm{Goal}+$ Source $)$ is the reason for the selection of BE.

Ethic reflexive with a monovalent verb (case $3 b)$ :

$\begin{array}{clll}\text { (23) Petru si hè } & \text { fermu } & \text { quì. } \\ \text { Peter CLIT be.PRS.3SG } & \text { stay.PTCP.M.SG } & \text { here } \\ \text { 'Peter stayed here.' } & & \end{array}$

There are two arguments (the subject and the clitic pronoun) corresponding to one actor. The clitic and the subject are co-referential. The clitic is a Source argument (Source in the sense of an agent with ghjucà/play, ciuttà/dive, firmà/stay, or a stimulus with esse and stà), and the subject Petru is both a Goal argument (Goal in the sense of beneficiary) intrinsically + a Source argument by means of its co-reference with the clitic. Petru si hè fermu quì can be glossed as Si has stayed for the benefit/to the detriment of Petru, with a locating relation of identification between Petru and si. The dual status of the subject (Goal + Source) is the reason for the selection of $\mathrm{BE}$.

\footnotetext{
Reciprocal reflexive without an object (case 4a):

The same kind of reasoning as above could be used, but the subject already has a dual status from the start because of the process itself, intrinsically. The dual status of the subject (Goal + Source) is the reason for the selection of BE.

Reflexive with a passive meaning, first with a bivalent verb (case $7 \mathrm{a}$ ):
(28) E ghjembe si sò tronche.
The branches CLIT be.PRS.3PL break.PTCP.F.PL

'The branches have broken.'

E ghjembe si sò tronche is close to the passive e ghjembe sò state tronche. However, as I showed above, this gloss is not reliable since a passive makes it possible to express an agent i.e. a Source argument, whereas a reflexive with a so-called passive meaning is not compatible with the presence of an agent; cf. (28/28') and (31/31'). The reason, which also confirms my invariant analysis 
of the reflexive construction, is that the reflexive construction already contains a Source argument (an exclusively Source argument) marked by $s i$, and therefore cannot take a second one. The difference between the reflexive with a passive meaning and the passive also concerns the subject: it is a Goal argument (an exclusively Goal argument) in a passive, but in a reflexive with a passive meaning like 28c the subject is not a Goal argument or more exactly it is not only a Goal argument, since it has a dual status.

I would like to elaborate slightly on the dual status of the reflexive with a passive meaning. For this reflexive, I have to make a distinction between two levels of Source: a Primary Source, and a Secondary Source. There is a Primary Source, which is outside the sentence. It is this source that cannot be made explicit by means of an agent introduced by $d a$ (by) in the sentence (cf. 28'). As for si, it is a Source argument, but a Secondary one. And the subject is co-referential with it.

"Secondary Source" means that the subject does not merely undergo the process (a process whose instigator is an outside argument, i.e. the Primary Source), but it is also partly responsible for it. This is because it possesses the necessary qualities for the realisation of the process, and these qualities are involved in the realisation of the change of state. For example when one says 28 e ghjembe si sò tronche the main cause of the breaking of the branches is indeed taken on by a Primary Source, for example Petru or $u$ ventu, but as a second resort there is a secondary cause of the breaking which is the branches themselves, embodied by si, with which $e$ ghjembe is co-referent. Si embodies the Source dimension obtained by the grammatical subject through the co-reference. The branches essentially broke because there was too much pressure on them, but even if the branches did not directly break the branches, $e$ ghjembe si so tronche means that the breaking of the branches is partly ascribable to the branches, whose solidity was not sufficient. Using Levin and Rappaport Hovav's terminology with bare intransitives ${ }^{42}$, one could almost claim that truncassi within a pronominal construction is both an external and internal causation verb, except that here the responsibility is only partial: this Corsican construction has the capacity of ranking the responsibilities between a Primary external Source and a Secondary internal one. An unspecified Primary Source

42 "With an intransitive verb describing an internally caused eventuality, some property inherent to the argument of the verb is responsible for bringing about the eventuality [...] Unlike internally caused verbs, externally caused verbs by their very nature imply the existence of an "external cause" with immediate control over bringing about the eventuality described by the verb: an agent, an instrument, a natural force, or a circumstance." (Levin and Rappaport Hovav 1995: 91-92). 
(Petru or $u$ ventu) acts upon ghjembe, which is a Goal argument but also the Secondary Source, because the language takes into account the existence of a Secondary Source that shows some agentivity or rather some responsibility on the part of the subject.

This is in line with the interpretation of 28 , is coherent with the argument and themactic status I gave of si, and in fine the dual status of the subject (Goal, + Source through the coreference with the Source argument) is the reason for the selection of BE, as it was with reflexive forms other than the passive reflexive and with non-reflexive intransitives.

This is also the difference between reflexive 28c E ghjembe si sò tronche and nonreflexive $E$ ghjembe hanu troncu:

(28) E ghjembe si sò tronche.

The branches CLIT be.PRS.3PL break.PTCP.F.PL

'The branches have broken (themselves).'

(34) E ghjembe hanu troncu.

The branches have.PRS.3PL break.PTCP.M.SG

'The branches have broken.'

The reflexive construction selects BE because the subject has a dual status, whereas the non-reflexive construction selects HAVE because the subject does not have a dual status and is not a Secondary Source. It is not a Secondary Source because it bears no responsibility for the realisation of the process. Three forms can be compared from the active voice 35:

(35)Xhà troncu e ghjembe (active meaning and active morphology)

X have.PRS.3SG break.PTCP.M.SG the branches

'X has broken the branches.'

(34) E ghjembe hanu troncu (*daX) (passive meaning and active morphology)

The branches have.PRS.3PL break.PTC (*by X)

P.M.SG

'The branches have broken (*by X).'

(31)E ghjembe sò state tronche $(* d a X) \quad$ (passive meaning and passive morphology)

The branches be.PRS.3be.PASS.PTCP. break.PTCP. (*by X)

PL F.PL F.PL

'The branches have been broken (*by X).' 


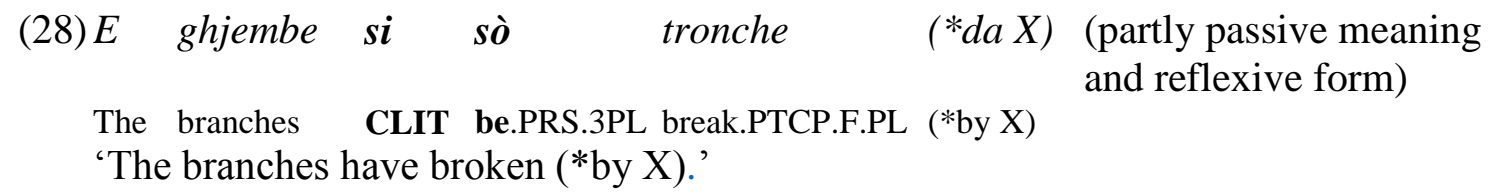

34 e ghjembe hanu troncu is an example of a reversible verb: it has a passive meaning and active morphology, and it does not licence an external argument because there is no Source. Unlike 28, 34 is a lexical phenomenon limited to certain verbs (for the kinds of verbs possible see for example Heidinger and Schäfer 2008: 138 ff. or Schäfer 2008: 187 ff.). There is no Source, whether Primary or Secondary, and because of this absence of cause they are called "anticausatives". Any derivational relationship with a bivalent construction in the active voice is artificial, whether the causative alternant is derived from the anticausative via causativisation (Pesetsky 1995, etc.) or the anticausative lacks an implicit external argument due to a process of detransitivisation (Reinhart 2002, etc.), precisely because with an anticausative the process is presented as spontaneous and agentless (Haspelmath 1993: 90), it expresses an "autonomous event", "occurring in and of itself (Talmy 2003: 472), without implying that it has a Source.

In 31 e ghjembe sò state tronche $(\mathrm{da} X)$, there is a passive meaning and passive morphology: there is one single Source, outside the sentence and explicitable in a da-phrase, and (when this Source is explicit) two arguments and two actors. It is a fundamentally bivalent construction, and a place must be reserved for the agent even when it is not mentioned.

Finally in 28 e ghjembe si sò tronche $(* d a X)$, which has a partly passive meaning and is a reflexive form, I shall argue there are two Sources: two co-referential arguments and therefore one actor. Two levels of Source with one Primary Source outside the sentence and not mentionable and a Secondary Source (embodied by the clitic pronoun with which the Goal subject is co-referential) responsible for the realisation of the process due to its qualities. The subject of reflexive $e$ ghjembe si sò tronche, but not of non-reflexive $e$ ghjembe hanu troncu, has a dual status. This is why the former, but not the latter, selects BE.

Finally we turn to monovalent unaccusative and unergative verbs: at first glance, the monovalent si travaglia and the monovalent si va could not be more similar, at least in simple (non-reflexive) forms. But as soon as one considers their corresponding compound forms 29 and 30, the difference is clear in the final vowel: 
$\begin{array}{rll}\text { (29) } S i \quad h \grave{e} & \text { travagliatu. } \\ \text { CLIT be.PRS.3SG } & \text { work.PTCP.M.SG } \\ \text { 'One has worked.' } & \\ \text { (30) } S i \quad h \grave{e} & \text { andati. } \\ \text { CLIT } & \text { be.PRS.3SG } & \text { leave.PTCP.M.PL }\end{array}$

'One has left.'

Within the group of monovalents, two cases must therefore be distinguished, corresponding to what the UH calls unaccusatives and unergatives. Unaccusatives accept a $\mathrm{BE}$ reflexive form and a past participle in the plural, while unergatives accept a BE reflexive form (but HAVE is grammatical, for instance si hà travagliatu) but a past participle in the singular. This is why we say si hè travagliatu-masc-sing and not *si hè travagliati-masc-pl. The number cannot vary, nor can the gender (*si hè travagliata-fem-sing, *si hè travagliatefem-pl).

Let us first take a closer look at unaccusatives, like si hè andati: since, in the compound forms, the past participle agrees in the plural while the auxiliary agrees in the singular, the past participle has to agree with a subject which must be plural, too. The question is: where is this subject? I contend that the past participle agrees with $s i$, i.e. si is a subject ${ }^{43}$. This why $a$ ghjente (people) can be substituted for it as a subject: si hè andati $=$ a ghjente sò andati. To be more precise, si is a subject that is grammatically singular but semantically plural: grammatically singular to take into account the auxiliary, which is singular, and semantically plural to take into account the past participle, which (with an unaccusative) is in the plural. ${ }^{44}$ Why is it semantically plural? Because it refers to an indeterminate human animate (the quantifier tutti (all) could be added, obviously in the masculine plural: si ci hè tutti andati / we all left), roughly synonymous with a ghjente (people) or omu in Corsican, or with French on (on y est tous allés). Note a ghjente and si cannot be used together, since they have the same function.

An unaccusative reflexive as in si hè andati selects BE, not because the subject (si), which is intrinsically a Goal-argument, has a double status by means of a co-reference with a Source Argument (this would describe the situation

${ }^{43}$ This subject faces a number of constraints listed in note 37 , all of which also affect the French pronoun on, a subject pronoun.

${ }^{44}$ It is a partial syllepsis, since the singular agreement only bears on the auxiliary. This is exactly the situation of the French pronoun on, which takes an auxiliary in the singular but can take a past participle in the plural: On est venus trop tôt / One is-SG come-PL too early. $(\mathrm{EAG})$ 
of the bivalent reflexive with a passive meaning) but because of the verb itself, qualified as unaccusative by the UH. It does not matter whether the subject is $s i$; what counts is the verb, and the analysis will depend on the verb. For instance si hè andati will be analysed like $i$ nostri crunachisti sò andati:

(36) I nostri crunachisti sò andati in Moulinserre è sò vultati cù ste maghjine di felicità. (BC) Our reporters are gone in Moulinsart and they are returned with these images of happiness 'Our reporters have gone to Moulinsart and they have come back with these images of happiness.'

The subject (si, just like $i$ nostri crunachisti) is an agent-Source and a patient-Goal because andà is a verb expressing a middle voice. Consequently the subject has a double status, and the auxiliary BE is selected.

Now let us turn to si hè travagliatu, whose auxiliary selection is the only one that escapes all possible explanations within our framework. In si hè travagliatu, si is a subject, just like it is in si hè andati. More precisely it refers to an indeterminate human animate and is plural. In this respect, there is no difference between the $s i$ of unaccusatives and the $s i$ of unergatives. With a verb such as travaglià, which selects HAVE in the non-reflexive form (unlike andà in si hè andati), one would not have expected si hè travagliatu but si hà travagliatu (and note that si hà travagliatu is grammatical). One would conclude that si hè andati, with an unaccusative, selects BE, while si hà travagliatu, with an unergative, selects HAVE. But this is not the case. Why does an unergative like travaglià, logically HAVE-selecting in a nonreflexive form, usually select $\mathrm{BE}$ in a reflexive form?

The selection of $\mathrm{BE}$ is not due to a passive: si hè travagliatu is not a passive because travaglià is monovalent while the Corsican passive is limited to bivalent verbs. It is not due to a double status of the subject by means of the verb: with a so-called unergative, the subject $s i$ is only a Source. Consequently, no double status can be considered the explanation of the selection of $\mathrm{BE}$, unlike unaccusatives. The explanation I provided for unaccusatives is not extendable to unergatives. It is not due to a double status of the subject by means of a coreference: the explanation I provided for bivalent verbs is not extendable to unergatives (it is not extendable to monovalent verbs in general) since $s i$ is not balanced with an intrinsic Goalargument that would have established a co-reference relationship between them. It is not due to the reflexive form in itself 
either because in Corsican this form does not require the selection of BE (unlike French or Italian): si hè travagliatu coexists alongside si hà travagliatu.

Si hè travagliatu, the form commonly used, is the one least expected: the past participle has no agreement while in the two types of monovalents the subject si refers to an indeterminate human in the plural and BE is selected - in other words an auxiliary usually going with an agreement.

Why is there no agreement? Is it because si is not a subject? We know it is. Is it because the subject si is not a plural? We know it is. The question that arises is then to know why the past participle agrees with si in the case of andà (unaccusative) but not in the case of travaglià (unergative). Our answer to this question is also our answer to the question of why a so-called unergative like travaglià, quite logically HAVE-selecting in a non-reflexive form, can select $\mathrm{BE}$ in a reflexive form. To make it short, our answer is: because the $\mathrm{BE}$ in si hè travagliatu is not a real BE: it is a BE with the properties of auxiliary HAVE. I think the lack of agreement in si hè travagliatu is revealing because, due to this lack of agreement, si hè travagliatu behaves as if its auxiliary were avè (HAVE), precisely the auxiliary you would expect with an unergative. Nevertheless, the monovalent unergative verb in Corsican is an exception among all the Corsican reflexive constructions. We leave this question open pending further research.

\section{Conclusion}

We started by voicing several criticisms: 1) the problems raised by the ASHS's gradient representation built on prototypical occurrences, as evident from both the mismatches with some data and the constitution of the gradient itself, 2) the problems raised without prototypical occurrences by scalarity in general because certain syntactic phenomena in context escape any kind of scalar representation and because the nature of the compound form of a specific language is a relevant factor that cannot be ignored and makes cross-linguistic scales problematic, and 3) the unjustified exclusion of reflexive verbs from the field of study of auxiliary selection.

This led us to propose a binary vision of auxiliaries that takes into account both simple intransitive verbs and reflexive verbs, one different from the Unaccusative Hypothesis. This vision, not so much quantitative in terms of thresholds but qualitative, aims at giving a specific explanation for each language under consideration regarding auxiliary selection. With regard to Corsican, the following global binary explanation is provided: HAVE is selected when the subject corresponds to a Source macro-role, while BE is selected (in the case of simple BE-verbs) or selectable (in the case of reflexive BE-verbs) when the 
subject corresponds to both Source and Goal macro-roles, i.e. it satisfies two thematic roles. The subject of simple BE-verbs has this dual status intrinsically, the subject of reflexive BEverbs satisfies this dual status either intrinsically obtains it mostly by means of a co-reference with the clitic pronoun treated not as a valency-reducing marker but as an argument. Reflexive verbs give rise to a second binary distinction: BE is actually selected when, in the presence of a bivalent verb and an explicit object ${ }^{45}$, the subject is topicalised, while HAVE is selected when the object is topicalised.

\section{References}

Aarts, Bas. 2007 Syntactic Gradience: the Nature of Grammatical Indeterminacy. Oxford: Oxford University Press.

Alexiadou, Artemis and Elena Anagnostopoulou. 2004 Voice Morphology in the Causative-Inchoative Alternation. In: Artemis Alexiadou, Martin Everaert and Elena Anagnostopoulou (eds.) The Unaccusativity Puzzle: Explorations of the Syntax-Lexicon Interface, 114-136. Oxford: Oxford University Press.

Bentley, Delia and Eyrthorsson Thorhallur. 2003 Auxiliary Selection and the Semantics of Unaccusativity. Lingua 114: 447-471.

Benveniste, Émile. $1974 \quad$ Problèmes de linguistique générale. Paris : Gallimard.

Borer, Hagit. 1994 The Projection of Arguments. In: Elena Benedicto and Jeffrey Runner (eds.), Functional Projections, 19-47. (University of Massachusetts Occasional Papers 17.) Amherst: Graduate Linguistic Student Association.

Burzio, Luigi. $1981 \quad$ Intransitive Verbs and Italian Auxiliaries. PhD Dissertation, MIT.

Burzio, Luigi. $1986 \quad$ Italian Syntax, a Government-Binding Approach. Dordrecht: Reidel.

Cennamo, Michela and Antonella Sorace. 2006 Auxiliary Selection and Split Intransitivity in Paduan. In: Raul Aranovich (ed.), Split Auxiliary Systems: a Cross-Linguistic Perspective, 65-99. (Typological Studies in Language 69.) Amsterdam, Philadelphia: John Benjamins.

Culioli, Antoine. 1990 Pour une linguistique de l'énonciation. Tome 1, Paris : Ophrys.

Culioli, Antoine. 1991-92 Structuration d'une notion et typologie lexicale. BULAG 17: 7-12.

Culioli, Antoine. 1999 Pour une linguistique de l'énonciation. Tome 2, Paris : Ophrys.

Dobrovie-Sorin, Carmen. 1998 Impersonal SE Constructions in Romance and the Passivization of Unergatives. Linguistic Inquiry 29: 399-437.

Embick, David. 2004 Unaccusative Syntax and Verbal Alternations. In: Artemis Alexiadou, Martin Everaert and Elena Anagnostopoulou (eds.), The Unaccusativity Puzzle: Explorations of the Syntax-Lexicon Interface, 137-158. Oxford: Oxford University Press.

Giancarli, Pierre-Don. 2011 Les Auxiliaires ÊTRE et AVOIR : étude comparée corse, français, acadien et anglais. Rennes : Presses Universitaires de Rennes.

Gundel, Jeanette. 1988 Universals of topic-comment structure. In: Michael Hammond, Edith Moravcsik and Jessica Wirth (eds.), Studies in Linguistic Typology, 209-239, Amsterdam, Philadelphia, John Benjamins.

Gurman Bard, Ellen, Cheryl Frenck-Mestre and Antonella Sorace. 2010 Processing Auxiliary Selection with Italian Intransitive Verbs. Linguistics 48: 325-361.

${ }^{45}$ One exception: BE is also selectable with monovalent unergatives. 
Hale, Kenneth and Samuel Keyser.2002 Prolegomenon to a Theory of Argument Structure. Cambridge, Mass.: MIT Press.

Härtl, Holden. 2003 Conceptual and Grammatical Characteristics of Argument Alternations. The Case of Decausative Verbs. Linguistics 41: 883-916.

Heidinger, Steffen and Florian Schäfer. 2008 The French Reflexive Passive and Anticausative. In: Benjamin Fagard, Sophie Prévost, Bernard Combettes and O. Bertrand (eds.), Évolutions en français, Études de linguistique diachronique, 135-152. Bern : Peter Lang.

Herslund, Michael. 1996 Det franske sprog [The French Language], Kapitel III, Valens og transitivitet. Forelobig version.

Kallulli, Dalina. 2006 On unaccusative morphology and argument realization. Unpublished manuscript, University of Vienna.

Kayne, Richard S. $\quad 1988 \quad$ Romance SE / SI, GLOW Newsletter 20: 33.

Keller, Frank and Antonella Sorace. 2003 Gradient Auxiliary Selection in German. Journal of Linguistics 39: 57-108.

Legendre, Géraldine. $\quad 2007$ On the Typology of Auxiliary Selection, Lingua 117: 1522-1540.

Legendre, Géraldine and Antonella Sorace. 2003 Auxiliaires et intransitivité en français et dans les langues romanes. Les Langues Romanes, Sciences du Langage, CNRS Editions: 185-233. English version at http://www.cog.jhu.edu/faculty/legendre/index.htm

Levin, Beth and Malka Rappaport Hovav. 1995 Unaccusativity: At the Syntax-Semantics Interface.

Cambridge, Mass.: MIT Press.

McFadden, Thomas. $\quad 2007$ Auxiliary selection. Language and Linguistics Compass 1: 674-708.

Perlmutter, David. 1978 Impersonal Passives and the Inaccusative Hypothesis. In: Jeri Jaeger and Anthony Woodbury (eds.), Proceedings of the Fourth Annual Meeting of the Berkeley Linguistic Society, 157189. University of California at Berkeley.

Perlmutter, David. $\quad 1980 \quad$ Relational Grammar. In: Edith Moravcsik and Jessica Wirth (eds.), Syntax and Semantics 13: Current Approaches to Syntax, 195-229. New York: Academic Press.

Pesetsky, David. 1995 Zero Syntax. Cambridge, Mass.: MIT Press.

Reinhart, Tanya. 2002 The theta system: An overview. Theoretical Linguistics 28: 229-290.

Reinhart, Tanya and Tal Siloni. $\quad 2005$ The Lexicon-Syntax Parameter. Linguistic Inquiry 36: 389-436.

Rizzi, Luigi. 1986 On Chain Formation. In: Hagit Borer (ed.), Syntax and Semantics. vol. 19. The Syntax of Pronominal Clitics, 65-95. New York: Academic Press.

Rosen, Carol. 1984 The Interface between Semantic Roles and Initial Grammatical Relations. In: David Perlmutter and Carol Rosen (eds.), Studies in Relational Grammar 2: 38-77. Chicago: University of Chicago Press.

Ruwet, Nicolas. 1988 Les verbes météorologiques et l'hypothèse inaccusative. In: Claire BlancheBenveniste, André Chervel and Maurice Gross (eds.), Grammaire et Histoire de la Grammaire. Hommage à la mémoire de Jean Stéfanini, 383-402. Université de Provence.

Schäfer, Florian. 2008 Middles as Anticausatives. In: Emily Efner and Martin Walkow (eds.), Proceedings of NELS 37: 183-196. Amherst: Graduate Linguistic Student Association. 
Sorace, Antonella. $\quad 2000 \quad$ Gradients in Auxiliary Selection with Intransitive Verbs. Language 76: 859890.

Sorace, Antonella. $\quad 2004$ Gradience at the Lexicon-Syntax Interface. In: Artemis Alexiadou, Martin Everaert and Elena Anagnostopoulou (eds.) The Unaccusativity Puzzle: Explorations of the Syntax-Lexicon Interface, 243-268. Oxford: Oxford University Press.

Sorace, Antonella. 2006 Gradedness and Optionality in Mature and Developing Grammars. In: Gisbert Fanselow, Caroline Fery, Matthias Schlesewsky and Ralph Vogel (eds.), Gradience in Grammars, 106123. Oxford: Oxford University Press.

Sorace, Antonella. $2011 \quad$ Gradience in Split Intransitivity: the End of the Unaccusativity Hypothesis? Archivio Glottologico Italiano 96: 67-86.

Sorace, Antonella and Frank Keller. $2005 \quad$ Gradience in Linguistic Data. Lingua 115: 1497-1524.

Talmy, Leonard. 2003 Toward a Cognitive Semantics. Cambridge, Mass.: The MIT Press.

Tenny, Carol. 1992 The Aspectual Interface Hypothesis. In , Ivan Sag and Anna Szabolsci (eds.), Lexical Matters, 1-27. Stanford: Center for the Study of Language and Information.

Van Valin, Robert. $\quad 1990 \quad$ Semantic Parameters of Split Intransitivity. Language 66: 221-260.

Van Valin, Robert and Randy Lapolla. 1997 Syntax: Structure, Meaning and Function. Cambridge: Cambridge University Press.

\section{Corpus}

Acadian:

Corpus Péronnet "85". A corpus of traditional Acadian consisting of 75,000 words recorded in southeast New Brunswick, Canada.

French and Corsican:

The French and Corsican corpora, which amount to 405,327 and 353,212 words respectively, are composed of the following texts ${ }^{46}$ :

Antoni, Petru. $2000 \quad$ Detti è fatti. La Marge. (DF)

Beckett, Samuel. [1948] 1988 En Attendant Godot. Les Éditions de Minuit. Corsican translation by D. Geronimi 1985 Intantu. In: Rigiru 23 Éditions Cyrnos et Méditerranée. (EAG)

Biancarelli, Marcu. $2001 \quad$ San Ghjuvanni in Patmos. Albiana. (SGP)

Collodi, Carlo. [1883] 2002 Les aventures de Pinocchio. Corsican translation by G. Fusina 2001 Pinochju. Éditions Stamperia Sammarcelli. (P)

Daudet, Alphonse. [1873] $2001 \quad$ Contes du lundi. Gallimard. Corsican translation by M. Ceccaldi 1980 Fole di u luni. Klincksieck. (CDL)

Delmon-Casanova, Jean-Luc. $2002 \quad$ Heresia. DCL Éditions. Corsican translation by S. Casta. (H)

Giacomo-Marcellesi, Mathée. 1989 Contra Salvatica. Edisud. (CS)

\footnotetext{
${ }^{46}$ The corresponding abbreviations are given in brackets.
} 
Hergé. 1963 Les bijoux de la Castafiore. Casterman. Corsican translation by F.-M. Perfettini 1994 I ghjuvelli di a Castafiore. Casterman. (BC)

Saint-Exupery, Antoine de. [1943] $1990 \quad$ Le Petit Prince. Gallimard. Corsican translation by S. Casta 1990 U Principellu. Akenaton \& Squadra di u Finusellu. (PP)

Thiers, Jacques. 1990 A Funtana d'Altea, Albiana. (AFA)

Thiers, Jacques. 1996 A barca di a Madonna. Albiana. (ABM) 